\title{
Foreword
}

\section{Meniscal Repair: The R-Factor}

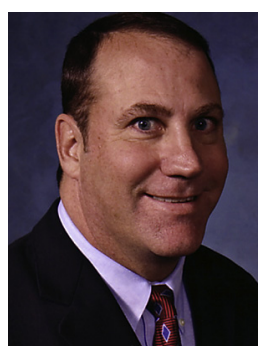

Mark D. Miller, MD

Consulting Editor

Although I am far from an expert in molecular biology, I do recall that the R-factor is named for a plasmid that codes for antibiotic resistance. The R-factor for the meniscus should be that we Resist any attempt to Remove this vital structure unless there is no other alternative. This issue of Clinics in Sports Medicine, expertly edited by Drs Brett Owens and Ramin Tabaddor, follows an R-factor theme of sorts. The articles begin with a discussion of the Role of the meniscus and the Results of Removal. The issue then focuses on techniques for Repair and Replacement. Removal should always be the last option, but is sometimes unavoidable. Finally, Rehabilitation and Return to play are addressed.

I have been an advocate of meniscal preservation my entire career. Twenty-five years ago, we published an article that demonstrated the importance of meniscal repair in an animal model. ${ }^{1}$ That same year, I was invited to be a Guest Editor for Operative Techniques in Orthopaedics and made a plea to the readers to "Save the Meniscus." Despite all that we have learned about the meniscus in the past quarter century ("ramp lesions," root tears, salvaging radial and horizontal tears, new techniques for meniscal transplantation, and so forth), I find myself once again repeating 
this plea. Remember the R-factor: Repair Regularly, Resect Rarely. Save the Meniscus!

Mark D. Miller, MD Division of Sports Medicine Department of Orthopaedic Surgery University of Virginia James Madison University 400 Ray C. Hunt Drive, Suite 330 Charlottesville, VA 22908-0159, USA

E-mail address: mdm3p@virginia.edu

\section{REFERENCE}

1. Miller MD, Ritchie JR, Gomez BA, et al. Meniscal repair. An experimental study in the goat. Am J Sports Med 1995;23(1):124-8. 